Supplement of Biogeosciences, 17, 1701-1715, 2020

https://doi.org/10.5194/bg-17-1701-2020-supplement

(C) Author(s) 2020. This work is distributed under

the Creative Commons Attribution 4.0 License.

(c) (1)

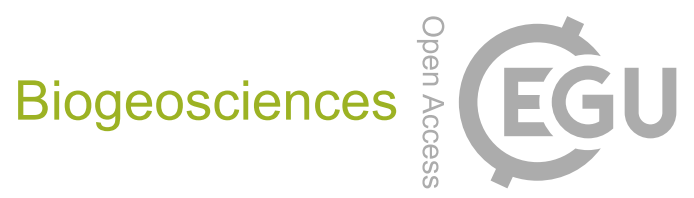

Supplement of

\title{
Biological and biogeochemical methods for estimating bioirrigation: a case study in the Oosterschelde estuary
}

Emil De Borger et al.

Correspondence to: Emil De Borger (emil.de.borger@nioz.nl)

The copyright of individual parts of the supplement might differ from the CC BY 4.0 License. 


\section{S1 Calculation of equilibrium constant.}

The calculation of the equilibrium constant $E q_{A}\left(\mathrm{~mL} \mathrm{~g}^{-1}\right)$ was done for sediment from incubation cores of Dortsman and Zandkreek. The $E q_{A}$ value was determined from batch adsorption experiments.

\section{S1.1 Sensor calibration}

5 A fluorescence spectrophotometer (Varian Cary Eclipse fluorescence spectrophotometer) was calibrated with a dilution series of uranine. Uranine solutions of $0 \mu \mathrm{g} / \mathrm{L}, 2 \mu \mathrm{g} / \mathrm{L}, 5 \mu \mathrm{g} / \mathrm{L}, 10 \mu \mathrm{g} / \mathrm{L}, 15 \mu \mathrm{g} / \mathrm{L}$ and $20 \mu \mathrm{g} / \mathrm{L}$ were prepared by diluting a starting concentration of $1 \mathrm{mg} \mathrm{L}^{-1}$ of uranine salts (sodium fluoresceine $-\mathrm{C}_{20} \mathrm{H}_{10} \mathrm{NaO}_{5}^{-}$) in $0.2 \mu \mathrm{m}$ filtered Oosterschelde water. The fluorescence (RFUB) of each concentration was determined in $10 \mathrm{~mm} \times 10 \mathrm{~mm}$ cuvettes, for an excitation wavelength $\lambda_{\text {exc }}$ of $494 \mathrm{~nm}$, and an emission wavelength $\lambda_{\text {emi }}$ of $513 \mathrm{~nm}$ (Gerke et al., 2013). This delivered the following calibration line (Eq. S1)

10 with $\mathrm{R}^{2}=0.998$ :

$R F U B=0.565+3.085 \cdot$ Concentration $\left(\mu g L^{-1}\right)$

\section{S1.2 Sediment adsorption}

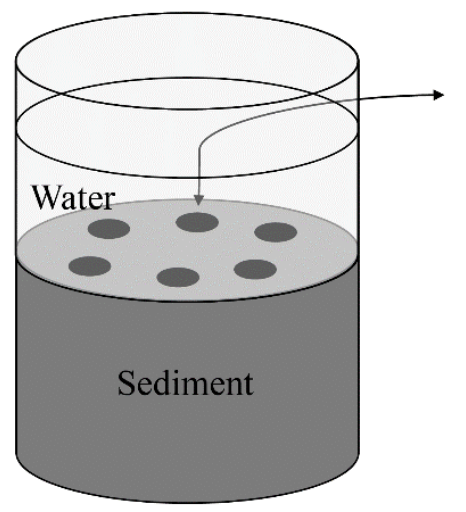

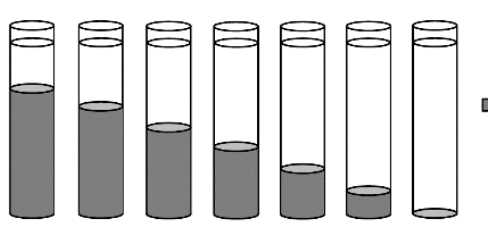

$F_{w}$ : Fluorescence of water

$F_{m}$ : Fluorescence water-sediment mix

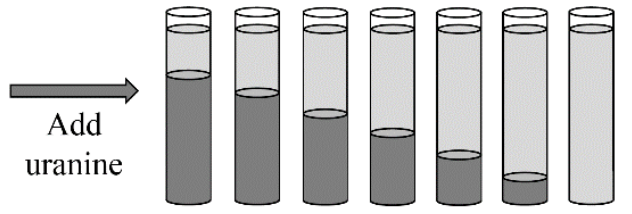

$F_{c}$ : Fluorescence spike blank cores $F_{e}$ : Fluorescence spiked water-sediment mix after 24 hours (equilibrium)

Figure S1: Batch adsorption experiment design, and explanation of the measured fluorescence values.

15 Additional Ø $14 \mathrm{~cm}$ sediment cores were collected from Zandkreek, and Dortsman for batch adsorption experiments. These cores were left to left to equilibrate for 48 hours with the same setup as per materials and methods in the main manuscript. Subsequently 7 subcores ( $3.6 \mathrm{~cm}$ diameter) were collected with increasing amounts of sediment, starting from $0 \mathrm{~cm}$ of sediment (only overlying water) (Fig. S1). An initial sample was taken from the overlying water and measured as the $F_{w}$ (RFUB water). Subsequently the subcores were vigorously shaken for 1 minute, and left on a shaking table for 12 hours (in previous tests it

20 became clear that substances could leech out of the sediment, thus affecting the fluorescence reading. With this step it is ensured that all substances are in equilibrium), after which a second sample was taken as the $F_{m}$ value (RFUB sediment-water 
mixture). The overlying water in the cores was then spiked with uranine, with $3 \mathrm{~mL}$ of a $1 \mathrm{mg} \mathrm{L}^{-1}$ uranine stock solution, and cores were vigorously shaken for 1 minute. The $F_{c}$ (RFUB of the initial spike) was calculated afterwards, from the water volume in the core (overlying water volume + porewater volume), and the spike concentration. The cores were then placed on

25 the shaking table, to keep the overlying water in movement, for 24 hours. After 24 hours the fluorescence was measured again to obtain $F_{e}$ values (RFUB equilibrium). After the experiment, the overlying water was collected, and the volume determined. Also the sediment was collected, and freeze dried to acquire the sediment mass Msed. The difference between the wet, and the dried sediment mass was used to calculate the total volume of water $(\mathrm{Vol})$ in the core.

Throughout this experiment each measurement was performed by removing a volume of $10 \mathrm{~mL}$ of sample, into a $15 \mathrm{~mL}$

30 centrifuge tube. The sample was then centrifuged for 6 minutes at $1500 \mathrm{rpm}$ to remove colloids from suspension, which affect the fluorescence reading in a non-replicable way. The extracted sample was then added again to the core.

\section{S1.3 Calculations}

The adsorbed equilibrium concentration ( $\mu \mathrm{g}$ uranine adsorbed $\mathrm{g}^{-1}$ dry sediment) is calculated by dividing the initial spike concentration $\left(F_{c}-F_{w}\right)$ minus the equilibrium concentration $\left(F_{e}-F_{m}\right)$ by the sediment concentration in each subcore:

$35 q_{a d s}=\frac{\left(\left(F_{c}-F_{w}\right)-\left(F_{e}-F_{m}\right)\right) \times \mathrm{Vol}}{\text { Msed }}$

The water equilibrium concentration $\left(\mu \mathrm{g}\right.$ uranine $\left.\mathrm{L}^{-1}\right)$ :

$C_{e}=F e-F m$

The equilibrium constant $\left(\mathrm{mL} \mathrm{g}^{-1}\right)$ is then the amount of uranine adsorbed by the sediment, divided by the equilibrium concentration in the water:

$40 \quad E q_{A}=\frac{q_{a d s}}{C_{e}}$

$E q_{A}$ in $\mathrm{mL} \mathrm{g}^{-1}$

\section{S1.4 Results}

Table S1: $E q_{A}$ calculated form the batch adsorption tests, with the respective sediment concentrations.

\begin{tabular}{cccc}
\hline \multicolumn{2}{c}{ Dortsman } & \multicolumn{2}{c}{ Zandkreek } \\
$\mathbf{c S e d}\left(\mathbf{g ~ L}^{\mathbf{- 1}}\right)$ & $\boldsymbol{E q}_{\boldsymbol{A}}\left(\mathbf{m L ~ g}^{-\mathbf{1}}\right)$ & $\mathbf{c S e d}\left(\mathbf{g ~ L}^{-\mathbf{1}}\right)$ & $\boldsymbol{E q}_{\boldsymbol{A}}\left(\mathbf{m L ~ \mathbf { ~ } ^ { - \mathbf { 1 } } )}\right.$ \\
\hline 398.7 & 0.0161 & 329.4 & 0.0431 \\
364.5 & 0.0559 & 309.7 & 0.0536 \\
490.3 & 0.004 & 493.3 & 0.0416 \\
550.3 & 0.0221 & 676.7 & 0.0757 \\
744.6 & 0.0836 & 831.5 & 0.0211 \\
818.3 & 0.0128 & 956.1 & 0.0153 \\
Average \pm sd: & $0.0324 \pm 0.0308$ & Average $\pm \mathbf{~ s d :}$ & $0.0417 \pm 0.022$ \\
\hline
\end{tabular}


45 Table $\mathrm{S} 1$ shows the results of the batch adsorption tess. Because of the similarity between $E q_{A}$ calculated for both sediments, and the small influence this parameter has based on the sensitivity analysis, the parameter value was fixed on an average value of $0.05 \mathrm{~mL} \mathrm{~g}^{-1}$.

\section{S2 Testing adsorption of uranine to incubation setup, and living organic matter.}

To test the adsorption of uranine to the incubation setup, or living organic matter, two side-experiments were performed. In a

50 first experiment (Fig. S2b) cores which were either aerated with a bubbling stone, or not aerated were spiked with uranine. In the second experiment (Fig. S2a) six live cockles were placed into duplicate aerated incubation cores, and then spiked with uranine. In both experiments the tracer concentrations were closely monitored for $23-25$ hours, to check whether uranine would adsorb to a biological or artificial surface. Results of these tests indicated that there was no cause for further investigation of the adsorption properties of uranine to the experimental setup.

\section{C. edule experiment}

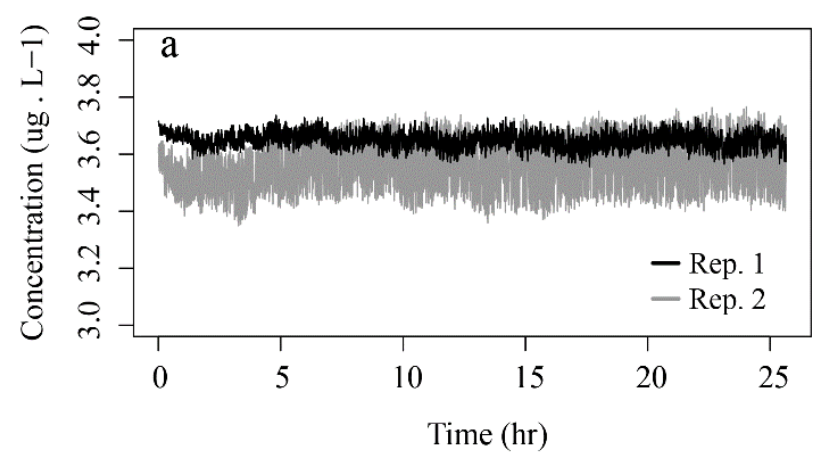

Blanks experiment

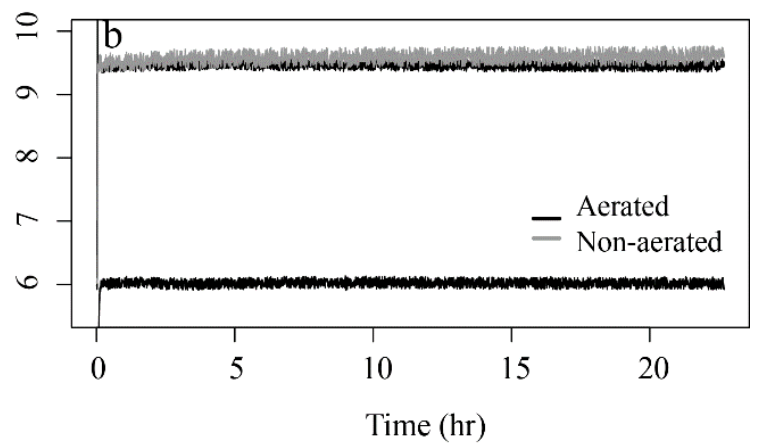

Figure S2: $a$. Concentration of uranine over time in duplicate cores containing six live cockles each. $b$. Two cores aerated with a bubbling stone (black), and one non-aerated core (gray). For the aerated core two concentrations were tested to assess whether this would have any impact.

\section{S3 Species scores.}

60 Table S2: Scores for the BPc (BPc_R: reworking score, BPc_M: mobility score, BPc_Ft: feeding type), and for IP (IPc_Ft = feeding type, IPc_D = injection pocket depth).

\begin{tabular}{lcccccc}
\hline Taxa & BPc_R & BPc_M & BPc_Ft & Ipc_Bt & Ipc_Ft & Ipc_D \\
\hline Abra alba & 2 & 2 & $\mathrm{~S}$ & 1 & 1 & 3 \\
Abra prismatica & 2 & 2 & $\mathrm{~S}$ & 1 & 1 & 3 \\
Abra tenuis & 2 & 2 & $\mathrm{~S}$ & 1 & 1 & 3 \\
Actiniaria & 2 & 2 & $\mathrm{~S}$ & 1 & 2 & 1 \\
Ammothea hilgendorfi & 2 & 2 & $\mathrm{~S}$ & 1 & 3 & 1 \\
Arenicola marina & 3 & 2 & $\mathrm{UC}$ & 3 & 3 & 4
\end{tabular}




\begin{tabular}{|c|c|c|c|c|c|c|}
\hline Ascidiacea & 1 & 1 & $\mathrm{E}$ & 1 & 1 & 1 \\
\hline Asterias rubens & 1 & 3 & $\mathrm{E}$ & 1 & 2 & 1 \\
\hline Bathyporeia sp. & 2 & 3 & $S$ & 1 & 3 & 1 \\
\hline Capitella capitata & 3 & 2 & $\mathrm{UC}$ & 3 & 3 & 4 \\
\hline Carcinus maenas & 5 & 4 & $\mathrm{R}$ & 1 & 2 & 1 \\
\hline Cerastoderma edule & 2 & 2 & $S$ & 1 & 1 & 2 \\
\hline Cirripedia & 1 & 1 & $\mathrm{E}$ & 1 & 1 & 1 \\
\hline Corophium sp. & 2 & 4 & $S$ & 2 & 3 & 2 \\
\hline Crangon crangon & 2 & 4 & $S$ & 1 & 2 & 1 \\
\hline Crepidula fornicata & 1 & 1 & $\mathrm{E}$ & 0 & 0 & 0 \\
\hline Ensis sp. & 2 & 2 & $S$ & 1 & 1 & 4 \\
\hline Eteone longa & 4 & 3 & B & 1 & 2 & 1 \\
\hline Eunereis longissima & 4 & 4 & B & 3 & 3 & 3 \\
\hline Gattyana cirrhosa & 4 & 3 & B & 1 & 2 & 2 \\
\hline Glycera sp. & 4 & 3 & $\mathrm{~B}$ & 3 & 2 & 2 \\
\hline Glycera tridactyla & 4 & 3 & $\mathrm{~B}$ & 3 & 2 & 2 \\
\hline Hediste diversicolor & 4 & 4 & B & 3 & 3 & 4 \\
\hline Hemigrapsus sp. & 5 & 4 & $\mathrm{R}$ & 1 & 3 & 1 \\
\hline Heteromastus filiformis & 3 & 2 & $\mathrm{UC}$ & 3 & 3 & 4 \\
\hline Lanice conchilega & 3 & 1 & DC & 3 & 3 & 4 \\
\hline Limecola balthica & 2 & 2 & S & 1 & 3 & 3 \\
\hline Malacoceros sp. & 3 & 2 & $\mathrm{UC} / \mathrm{DC}$ & 3 & 3 & 4 \\
\hline Malmgrenia darbouxi & 4 & 3 & B & 1 & 2 & 4 \\
\hline Mediomastus fragilis & 3 & 2 & UC & 3 & 3 & 3 \\
\hline Melinna cristata & 3 & 1 & $\mathrm{UC} / \mathrm{DC}$ & 3 & 3 & 2 \\
\hline Mya sp. & 2 & 2 & $\mathrm{~S}$ & 1 & 1 & 4 \\
\hline Mysta picta & 4 & 3 & B & 1 & 2 & 1 \\
\hline Mytilus edulis & 1 & 1 & $\mathrm{E}$ & 1 & 1 & 1 \\
\hline Nematoda & 2 & 2 & $S$ & 1 & 1 & 1 \\
\hline Nemertea & 4 & 3 & $\mathrm{~B}$ & 2 & 2 & 2 \\
\hline Neoamphitrite figulus & 3 & 1 & $\mathrm{UC} / \mathrm{DC}$ & 3 & 3 & 2 \\
\hline Nephtys hombergii & 4 & 3 & B & 3 & 2 & 1 \\
\hline Nereididae & 4 & 3 & B & 3 & 2 & 1 \\
\hline Notomastus sp. & 3 & 2 & $\mathrm{UC}$ & 3 & 3 & 4 \\
\hline Ocenebra sp. & 2 & 4 & $\mathrm{~S}$ & 1 & 2 & 1 \\
\hline Oligochaeta & 4 & 3 & B & 3 & 3 & 2 \\
\hline Ophiura ophiura & 2 & 2 & $S$ & 1 & 3 & 1 \\
\hline Peringia ulvae & 2 & 3 & $S$ & 1 & 3 & 1 \\
\hline Pholoe baltica & 2 & 2 & S & 1 & 2 & 1 \\
\hline Phyllodoce тисоsa & 4 & 3 & B & 1 & 2 & 1 \\
\hline Platynereis dumerilii & 4 & 4 & B & 3 & 3 & 4 \\
\hline Polychaeta & 4 & 3 & B & 3 & 3 & 3 \\
\hline
\end{tabular}




\begin{tabular}{|c|c|c|c|c|c|c|}
\hline Polydora ciliata & 3 & 1 & $\mathrm{UC} / \mathrm{DC}$ & 1 & 1 & 2 \\
\hline Pygospio elegans & 3 & 1 & $\mathrm{UC} / \mathrm{DC}$ & 3 & 3 & 3 \\
\hline Ruditapes philippinarum & 2 & 2 & $S$ & 1 & 1 & 4 \\
\hline Scoloplos armiger & 4 & 3 & $\mathrm{~B}$ & 3 & 3 & 4 \\
\hline Scrobicularia plana & 2 & 2 & $\mathrm{~S}$ & 1 & 1 & 4 \\
\hline Sthenelais boa & 4 & 3 & $\mathrm{~B}$ & 1 & 2 & 1 \\
\hline Streblospio benedicti & 3 & 2 & $\mathrm{UC} / \mathrm{DC}$ & 1 & 2 & 1 \\
\hline Tellinoidea & 2 & 2 & $\mathrm{~S}$ & 1 & 1 & 3 \\
\hline Terebellidae & 3 & 1 & DC & 3 & 3 & 3 \\
\hline Tharyx sp. & 2 & 2 & $S$ & 3 & 3 & 2 \\
\hline Urothoe sp. & 2 & 3 & $\mathrm{~S}$ & 3 & 3 & 3 \\
\hline
\end{tabular}




\section{S4 Additional examples of fitted results/}
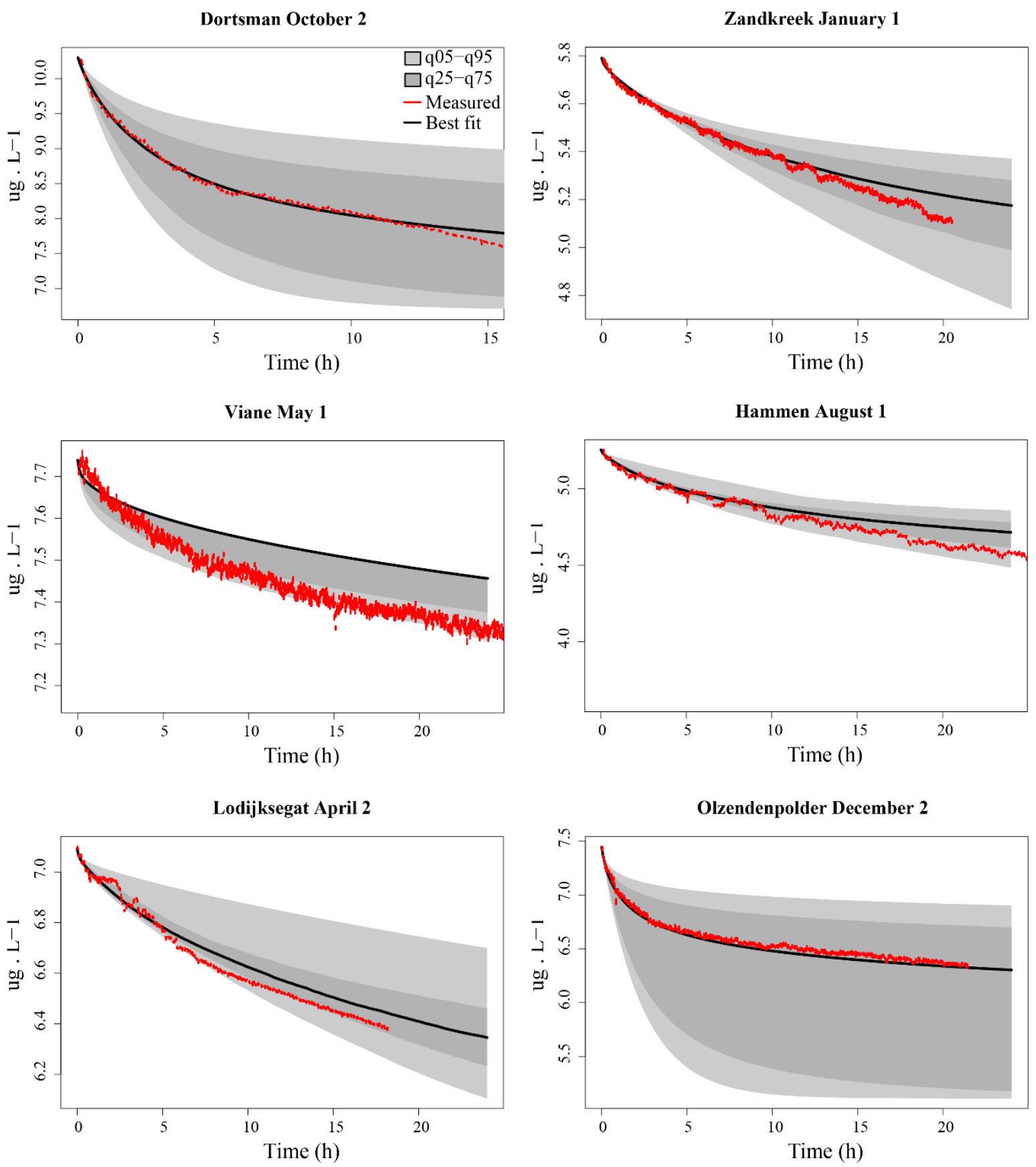

Figure S3: Additional model fits of data (red lines) collected different sites, at different times throughout the year. The best fit tracer profile (full black line) is shown, along with the range of model results as quantiles (light and dark grey). 


\section{Supplementary references}

Gerke, K.M., Sidle, R.C., Mallants, D., 2013. Criteria for selecting fluorescent dye tracers for soil hydrological applications using Uranine as an example. J. Hydrol. Hydromechanics 61, 313-325. doi:10.2478/johh-2013-0040 